
lymphocyte

\title{
Tumour-infiltrating CD8 + lymphocytes as an independent predictive factor for pathological complete response to primary systemic therapy in breast cancer
}

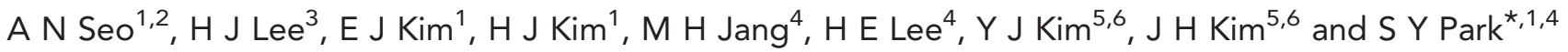

${ }^{1}$ Department of Pathology, Seoul National University Bundang Hospital, 300 Gumi-dong, Bundang-gu, Seongnam-si, Gyeonggi 463-707, Korea; ${ }^{2}$ Department of Pathology, Kyungpook National University School of Medicine, 680 Gukchaebosang-ro, Jung-gu, Daegu 700-842, Korea; ${ }^{3}$ Department of Pathology, Asan Medical Center, 88 Olympic-ro 43-gil, Songpa-gu, Seoul 138-746, Korea; ${ }^{4}$ Department of Pathology, Seoul National University College of Medicine, 28 Yeongon-dong, Jongno-gu, Seoul 110-799, Korea; ${ }^{5}$ Department of Medical Oncology, Seoul National University Bundang Hospital, 300 Gumi-dong, Bundang-gu, Seongnam-si, Gyeonggi 463-707, Korea and ' Department of Medical Oncology, Seoul National University College of Medicine, 28 Yeongondong, Jongno-gu, Seoul 110-799, Korea
\end{abstract}

Background: Tumour-infiltrating lymphocytes (TILs) are known to be associated with response to primary systemic therapy (PST) in breast cancer. This study was conducted to assess the association of TIL subsets with pathological complete response (pCR) after PST in breast cancer in relation to breast cancer subtype, breast cancer stem cell (BCSC) phenotype and epithelial-mesenchymal transition (EMT).

Methods: The pre-chemotherapeutic biopsy specimens of 153 breast cancer patients who underwent surgical resection after anthracycline- or anthracycline/taxane-based PST were analysed. TIL subsets (CD4+, CD8 +, and FOXP3+ TILs), BCSC phenotype, and the expression of EMT markers were evaluated by immunohistochemistry and were correlated with pCR after PST.

Results: Infiltration of CD4 + and CD8 + T lymphocytes was closely correlated with BCSC phenotype and EMT. High levels of $\mathrm{CD} 4+, \mathrm{CD} 8+$, and FOXP3 + TILs were associated with PCR, and CD8 + TILs were found to be an independent predictive factor for PCR. In addition, CD8 + TILs were associated with PCR irrespective of breast cancer subtype, CD44 + /CD24 - phenotype, $\mathrm{EMT}$, and chemotherapeutic regimen in subgroup analyses.

Conclusion: These findings indicate that CD8 + cytotoxic T lymphocytes are a key component of TILs associated with chemoresponse and can be used as a reliable predictor of response to anthracycline- or anthracycline/taxane-based PST in breast cancer.

Primary systemic therapy (PST) is considered the standard treatment for locally advanced breast cancer, and its use has substantially increased in recent years (Bear et al, 2003). PST facilitates breast-conserving surgery, initiates early systemic treatment for clinically undetectable micrometastases before surgery
(Chollet et al, 2002) and allows an evaluation of chemo-sensitivity of tumour against the given chemotherapeutic regimen (Melichar et al, 2012). Moreover, the degree of response to PST is considered an indicator of patient outcome, and the patients achieving pathological complete response (pCR) after PST have excellent

*Correspondence: Professor SY Park; E-mail: sypmd@snu.ac.kr

Received 6 July 2013; revised 22 September 2013; accepted 24 September 2013; published online 15 October 2013

(c) 2013 Cancer Research UK. All rights reserved 0007-0920/13 
disease-free and overall survival (Chollet et al, 2002). However, the clinical response to PST does not well correlate with the pathological response, and a precise evaluation of chemosensitivity to certain chemotherapeutic regimens can only be obtained by microscopic examination of residual tumour on surgical resection specimens after PST. Many studies have therefore been conducted to identify predictive factors for $\mathrm{pCR}$ after PST.

It has been shown that the immune system can eliminate tumour cells and control tumour growth by immunosurveillance (Swann and Smyth, 2007) and that the presence of tumourinfiltrating lymphocytes (TILs) is associated with favourable longterm outcome in breast cancer (Aaltomaa et al, 1992; DeNardo and Coussens, 2007; Schmidt et al, 2008). Moreover, a high level of TILs has been suggested to be a predictive factor for pCR in response to PST in breast cancer (Hornychova et al, 2008; Denkert et al, 2010; West et al, 2011; Ono et al, 2012; Lee et al, 2013). However, the subset of lymphocytes that is crucial in this respect has not been determined. CD8 + cytotoxic T lymphocytes (CTLs) have been shown to be associated with favourable response to anthracycline-based PST in breast cancer but have not been proved as an independent predictor of pCR (Ladoire et al, 2008; West et al, 2011).

In contrast to the ascribed protective role of tumour immunity, it has been demonstrated that the immune system, and CD $8+$ CTLs in particular, can induce tumours to undergo epithelialmesenchymal transition (EMT) and to acquire breast cancer stem cell (BCSC) properties and thus to have more aggressive behaviour (Reiman et al, 2010). BCSCs, represented by CD $44+/ C D 24-$ and aldehyde dehydrogenase 1 (ALDH1) expression, have been suggested to have an important role in chemo-resistance (Li et al, 2008; Tanei et al, 2009). EMT, which is regarded as an important mechanism of invasion by cancer cells and metastatic progression, was also reported to be associated with chemoresistance (Creighton et al, 2009; Singh and Settleman, 2010). Moreover, EMT is closely related to the BCSC phenotype (Mani et al, 2008). Thus, the possible association of TILs with BCSC and EMT seems to conflict with their effects on the chemo-response. However, the relationship of TILs to BCSC and EMT was not confirmed in human breast cancer samples, and it has not been shown that this relationship affects the significance of TILs as a predictive factor for $\mathrm{PCR}$ in breast cancer.

Among breast cancer subtypes, triple-negative or basal-like breast cancers are known to be more sensitive to anthracycline-based chemotherapy than luminal breast cancers (Carey et al, 2007; Bhargava et al, 2010). However, triple-negative breast cancer (TNBC) is characterised by conspicuous lymphocytic infiltration (Reis-Filho and Tutt, 2008) and, as we showed previously, is strongly associated with the BCSC phenotype and EMT (Park et al, 2010). Therefore, the predictive role of TILs in response to PST needs to be determined in the individual breast cancer subtypes, to avoid bias caused by their close relationship.

This study was designed to assess the association of TIL subsets with pCR in breast cancer patients who received antracycline- or antracycline/taxane-based chemotherapy as a function of breast cancer subtype, BCSC phenotype and EMT. For this purpose, we evaluated TIL subsets (CD4+, $\mathrm{CD} 8+$, and FOXP3 + ), BCSC phenotypes (CD44+/CD24-, and ALDH1), and the expression of EMT markers (vimentin, smooth muscle actin, osteonectin, E-cadherin, and N-cadherin) in pre-chemotherapeutic biopsy specimens and correlated them with pCR after PST in the total group of breast cancer patients and in subgroups according to breast cancer subtype, BCSC phenotype and EMT. We also examined the correlation of TILs with BCSC and EMT in total breast cancer and in the TNBCs.

\section{MATERIALS AND METHODS}

Patients and treatment. This retrospective study comprised 153 patients with clinical stage II $(n=78)$ or III $(n=75)$ breast cancer who underwent breast-conserving surgery or mastectomy after PST in Seoul National University Bundang Hospital from October 2004 to December 2010. All patient samples were obtained before PST by core needle biopsy and diagnosed as invasive breast carcinoma. Of the 153 patients, 66 (43.5\%) were treated with the AC regimen consisting of $60 \mathrm{mg} \mathrm{m}^{-2}$ doxorubicin i.v. on day 1 and $600 \mathrm{mg} \mathrm{m}^{-2}$ cyclophophamide i.v. on day 1 every 3 weeks for 4-6 cycles, and $40(26 \%)$ received sequential ACT comprising 4 cycles of $\mathrm{AC}$ followed by 4 cycles of $75 \mathrm{mg} \mathrm{m}^{-2}$ docetaxel, and the remaining $47(30.5 \%)$ received the $\mathrm{AD}$ regimen consisting of $50 \mathrm{mg} \mathrm{m}^{-2}$ doxorubicin i.v. on day 1 and $75 \mathrm{mg} \mathrm{m}^{-2}$ docetaxel i.v. on day 1 every 3 weeks for 3-6 cycles. The patients underwent breast surgery about 3-4 weeks after the last chemotherapy cycle.

A pair of formalin-fixed and paraffin-embedded tumour samples, consisting of a pre-chemotherapy biopsy and post-chemotherapy resection specimen, was collected for each patient. Medical records, pathology reports, $\mathrm{H} \& \mathrm{E}$-stained sections, and immunohistochemical slides for basic biomarkers were reviewed to acquire clinicopathological information, including age, sex, initial clinical $\mathrm{T}$ and $\mathrm{N}$ stage (by seventh UICC/AJCC), pathological $\mathrm{T}$ and $\mathrm{N}$ stage after PST, histological subtype (by WHO classification), histological grade (by Bloom and Richardson grading system), presence of carcinoma in situ, venous invasion, lymphatic invasion, tumour border, estrogen receptor (ER), progesterone receptor (PR), HER2 status, Ki-67 proliferation index, and p53 overexpression.

pCR was defined as the complete disappearance of all invasive tumour cells from breast tissue and regional lymph nodes regardless of the presence of residual ductal carcinoma in situ in the breast. This study was approved by an Institutional Review Board of Seoul National University Bundang Hospital (Protocol No. B-1206/160-301), and informed consent was waived.

Immunohistochemical staining. All immunohistochemical staining except double staining for CD44/CD24 was performed using an automatic immunostainer (BenchMark XT, Ventana Medical Systems, Tucson, AZ, USA) on pre-chemotherapy biopsy specimens. In brief, $4-\mu \mathrm{m}$ sections were transferred to glass slides coated with poly-L-lysine and dried overnight at $65^{\circ} \mathrm{C}$. They were then subjected to heat-induced antigen retrieval. Staining was optimised using positive and negative controls and primary antibodies directed against TIL markers (CD8, CD4, and FOXP3), BCSC markers (CD44, CD24, ALDH1), and EMT markers (vimentin, smooth muscle actin, osteonectin, N-cadherin, and E-cadherin; Supplementary Table S1). The sections were visualised with an UltraView Univeral DAB kit (Ventana Medical Systems).

Double immunostaining to detect CD $44+/ \mathrm{CD} 24-$ cells was performed with EnVision G|2 Doublestain System Rabbit/Mouse (diaminobenzidene (DAB) + /Permanent Red) (DAKO, Carpinteria, CA, USA) according to the manufacturer's instructions. CD44 was detected with DAB and CD24 with Permanent Red.

Quantification of tumour-infiltrating lymphocytes and scoring of markers. To evaluate the extent of TIL infiltration, we initially scanned all tumour biopsy cores in the immunohistochemically stained slides using $\times 4$ or $\times 10$ objective lens (OLYMPUS BX51, Olympus Optical Co., Ltd, Tokyo, Japan). If the TILs were homogeneously distributed, three high-power fields ( $\times 40$ objective) were selected at random for counting of TILs. In contrast, if its infiltration was heterogeneous, the areas with the highest and lowest infiltration were excluded, and five high-power fields were randomly selected in the rest. We photographed (OLYMPUS DP70 Digital Microscope Camera, Olympus Optical Co., Ltd) the selected representative high-power fields of each case and imported 
them into UTHSCSA Image Tool software (Version 3.0, Department of Dental Diagnostic Science at The University of Texas Health Science Center, San Antonio, TX, USA). Intratumoural lymphocytes were defined as lymphocytes within tumour cell nests and in direct contact with tumour cells, using the method of Denkert et al (2010), and intratumoural CD4 +, CD8 +, and FOXP3 + lymphocytes were quantified using the cell-counter function. Mean numbers of intratumoural $\mathrm{CD} 4+, \mathrm{CD} 8+$, and FOXP3 + TILs per field, and the ratios of $\mathrm{CD} 8+/ \mathrm{CD} 4+$, $\mathrm{CD} 4+/ \mathrm{FOXP} 3+$, and $\mathrm{CD} 8+/ \mathrm{FOXP} 3+\mathrm{TIL}$ were calculated. The median values of the TILs were used as cutoff values, and infiltration of the TILs was categorised as low or high.

The expression of BCSC and EMT markers was scored as the percentage of positive tumour cells in $10 \%$ increments. Details of the antibodies and the cutoff values used in the study are given in Supplementary Table S1.

Breast cancer subtypes. Breast cancer subtypes were categorised according to the St. Gallen Expert Consensus (Goldhirsch et al, 2011) as follows: luminal A type (ER + and/or PR +, HER2-, Ki$67<14 \%)$, luminal B (ER + and/or PR +, HER2-, Ki-67 $\geqslant 14 \%)$, luminal B/HER2 $+($ ER + and/or PR + , HER2 +$)$, HER2 + $(\mathrm{ER}-, \mathrm{PR}-, \mathrm{HER} 2+)$ and triple negative $(\mathrm{ER}-, \mathrm{PR}-$, HER $2-)$. For ER and PR, cases with $\geqslant 1 \%$ positive staining were considered positive. For HER2, $3+$ by immunohistochemistry or the presence of gene amplification by fluorescence in situ hybridisation was considered HER2 positive.

Statistical analysis. All statistical analyses were conducted using Statistical Package for the Social Sciences software (version 17.0, SPSS Inc, Chicago, IL, USA). Non-continuous data were compared by the Chi-square test or the Fisher's exact (two-sided) test, and continuous data were analysed by independent-samples $t$-test or the Mann-Whitney $U$ test. Spearman's rank correlation test was used to assess the correlation between markers. To detect independent predictive factors for $\mathrm{pCR}$, univariate and multivariate binary logistic regression analyses were performed. Backward stepwise model selection was used to build the multivariate logistic regression model, and any possibility of multicollinearity was excluded from the final model. Odds ratios (OR) and their 95\% confidence intervals (CI) were estimated for each factor. Statistical significance was set at $P<0.05$ for each analysis.

\section{RESULTS}

Patient characteristics. The clinicopathological characteristics of the patients included in this study are summarised in Table 1. Of the 153 patients, $20(13.1 \%)$ achieved pCR in the primary breast tissue and affected lymph nodes after PST. There was no statistical difference in pCR rate according to PST regimen, although it tended to be high in the subgroup receiving the ACT regimen. As expected, high histological grade $(P<0.001)$, ER negativity $(P<0.001)$, and high Ki-67 index $(P<0.001)$ were correlated with a higher pCR rate after PST. Of the molecular subtypes, TNBC had the highest $\mathrm{pCR}$ rate, significantly higher than in the luminal $\mathrm{A}$ and luminal B subtypes (triple-negative vs luminal A, $P<0.001$; triplenegative vs luminal $\mathrm{B}, P=0.002$ ).

TIL subsets and their association with the clinicopathological characteristics of tumours. We measured intratumoural infiltrates of $\mathrm{CD} 4+, \mathrm{CD} 8+$, and FOXP3 + T lymphocytes in each tumour. Infiltration was quite variable; some cases had prominent infiltrates, others had no infiltration (Figure 1). The relationships between infiltration of TIL subsets (low vs high) and various clinicopathological parameters of the tumours are shown in Table 2. High levels of infiltration of $\mathrm{CD} 4+, \mathrm{CD} 8+$, and

\begin{tabular}{|c|c|c|c|c|}
\hline & & $\begin{array}{c}\text { Non-pCR } \\
\text { group }\end{array}$ & $\begin{array}{c}\mathrm{pCR} \\
\text { group }\end{array}$ & \\
\hline Characteristics & $\begin{array}{c}\text { Total } \\
\mathbf{N}\end{array}$ & $\begin{array}{l}N \\
(\%)\end{array}$ & $\begin{array}{l}N \\
(\%)\end{array}$ & P-value \\
\hline $\begin{array}{l}\text { Age } \\
\text { Mean } \pm \text { s.d. }\end{array}$ & & $48.63( \pm 10.926)$ & $44.50( \pm 8.351)$ & 0.107 \\
\hline $\begin{array}{l}\text { Clinical stage } \\
\text { II } \\
\text { III }\end{array}$ & $\begin{array}{l}78 \\
75\end{array}$ & $\begin{array}{l}66(49.6) \\
67(50.4)\end{array}$ & $\begin{array}{r}12(60.0) \\
8(40.0)\end{array}$ & 0.387 \\
\hline $\begin{array}{l}\text { Clinical T stage } \\
\text { T1 } \\
\text { T2 } \\
\text { T3 } \\
\text { T4 }\end{array}$ & $\begin{array}{r}6 \\
93 \\
45 \\
9\end{array}$ & $\begin{aligned} 5 & (3.8) \\
82 & (61.7) \\
38 & (28.6) \\
8 & (6.0)\end{aligned}$ & $\begin{aligned} 1 & (5.0) \\
11 & (55.0) \\
7 & (35.0) \\
1 & (5.0)\end{aligned}$ & 0.926 \\
\hline $\begin{array}{l}\text { Clinical N stage } \\
\text { NO } \\
\text { N1-N3 }\end{array}$ & $\begin{array}{r}18 \\
135\end{array}$ & $\begin{array}{r}14(10.5) \\
119(89.5)\end{array}$ & $\begin{array}{r}4(20.0) \\
16(80.0)\end{array}$ & 0.259 \\
\hline $\begin{array}{l}\text { Histological subtype } \\
\text { IDC } \\
\text { ILC } \\
\text { Metaplastic carcinoma } \\
\text { Micropapillary carcinoma } \\
\text { Mucinous carcinoma }\end{array}$ & $\begin{array}{r}142 \\
6 \\
1 \\
2 \\
2\end{array}$ & $\begin{aligned} 123 & (92.5) \\
5 & (3.8) \\
1 & (0.8) \\
2 & (1.5) \\
2 & (1.5)\end{aligned}$ & $\begin{array}{l}19(95.0) \\
1(5.0) \\
0(0) \\
0(0) \\
0(0)\end{array}$ & 0.934 \\
\hline $\begin{array}{l}\text { Histological grade } \\
\text { Low (I and II) } \\
\text { High (III) }\end{array}$ & $\begin{array}{l}99 \\
54\end{array}$ & $\begin{array}{l}93(69.9) \\
40(30.1)\end{array}$ & $\begin{array}{r}6(30.0) \\
14(70.0)\end{array}$ & $<0.001$ \\
\hline $\begin{array}{l}\text { Estrogen receptor } \\
\text { Negative } \\
\text { Positive }\end{array}$ & $\begin{array}{r}53 \\
100\end{array}$ & $\begin{array}{l}39(29.3) \\
94(70.7)\end{array}$ & $\begin{array}{r}14(70.0) \\
6(30.0)\end{array}$ & $<0.001$ \\
\hline $\begin{array}{l}\text { HER2 status } \\
\text { Negative } \\
\text { Positive }\end{array}$ & $\begin{array}{r}118 \\
35\end{array}$ & $\begin{array}{r}106(79.7) \\
27(20.3)\end{array}$ & $\begin{array}{r}12(60.0) \\
8(40.0)\end{array}$ & 0.082 \\
\hline $\begin{array}{l}\text { Molecular subtype } \\
\text { Luminal A } \\
\text { Luminal B } \\
\text { Luminal B/HER2 + } \\
\text { HER2 + } \\
\text { Triple-negative }\end{array}$ & $\begin{array}{l}45 \\
36 \\
21 \\
13 \\
38\end{array}$ & $\begin{array}{l}45(33.8) \\
35(26.3) \\
16(12.0) \\
10(7.5) \\
27(20.3)\end{array}$ & $\begin{array}{c}0(0) \\
1(5.0) \\
5(25.0) \\
3(15.0) \\
11(55.0)\end{array}$ & $<0.001$ \\
\hline $\begin{array}{l}\text { Ki-67 proliferation } \\
\text { index } \\
\leqslant 20 \% \\
>20 \%\end{array}$ & $\begin{array}{l}76 \\
77\end{array}$ & $\begin{array}{l}74(55.6) \\
59(44.4)\end{array}$ & $\begin{array}{r}2(10.0) \\
18(90.0)\end{array}$ & $<0.001$ \\
\hline $\begin{array}{l}\text { Chemotherapy } \\
\text { regimen } \\
A C \\
A D \\
A C T\end{array}$ & $\begin{array}{l}66 \\
47 \\
40 \\
\end{array}$ & $\begin{array}{l}60(45.1) \\
42(23.3) \\
31(31.6)\end{array}$ & $\begin{array}{l}6(30.0) \\
5(25.0) \\
9(45.0) \\
\end{array}$ & 0.117 \\
\hline
\end{tabular}

Abbreviations: $\mathrm{AC}=$ doxorubicin plus cyclophosphamide; $\mathrm{ACT}=\mathrm{AC}$ followed by docetaxel; $A D=$ doxorubicin plus docetaxel; IDC = invasive ductal carcinoma; ILC = invasive lobular carcinoma; $\mathrm{PCR}=$ pathological complete response. $P$ values were calculated by independent sample $t$-tests and Chi-square or Fisher's exact tests.

FOXP3 $+\mathrm{T}$ lymphocytes were strongly associated with high histological grade $(P<0.001, P=0.003, P=0.002$, respectively), ER negativity $(P=0.006, P<0.001, P=0.001$, respectively $)$, triple-negative subtype $(P<0.001, P<0.001, P=0.002$, respectively), and high Ki-67 proliferation index $(P=0.003, P=0.043$, $P<0.001$, respectively). Although high level of infiltration of $\mathrm{CD} 4+\mathrm{T}$ lymphocytes was related to low clinical stage $(P=0.029)$, the infiltration of CD8 + and FOXP3 + T lymphocytes showed no relationships with clinical stage $(P=0.375$, $P=0.228$, respectively). 

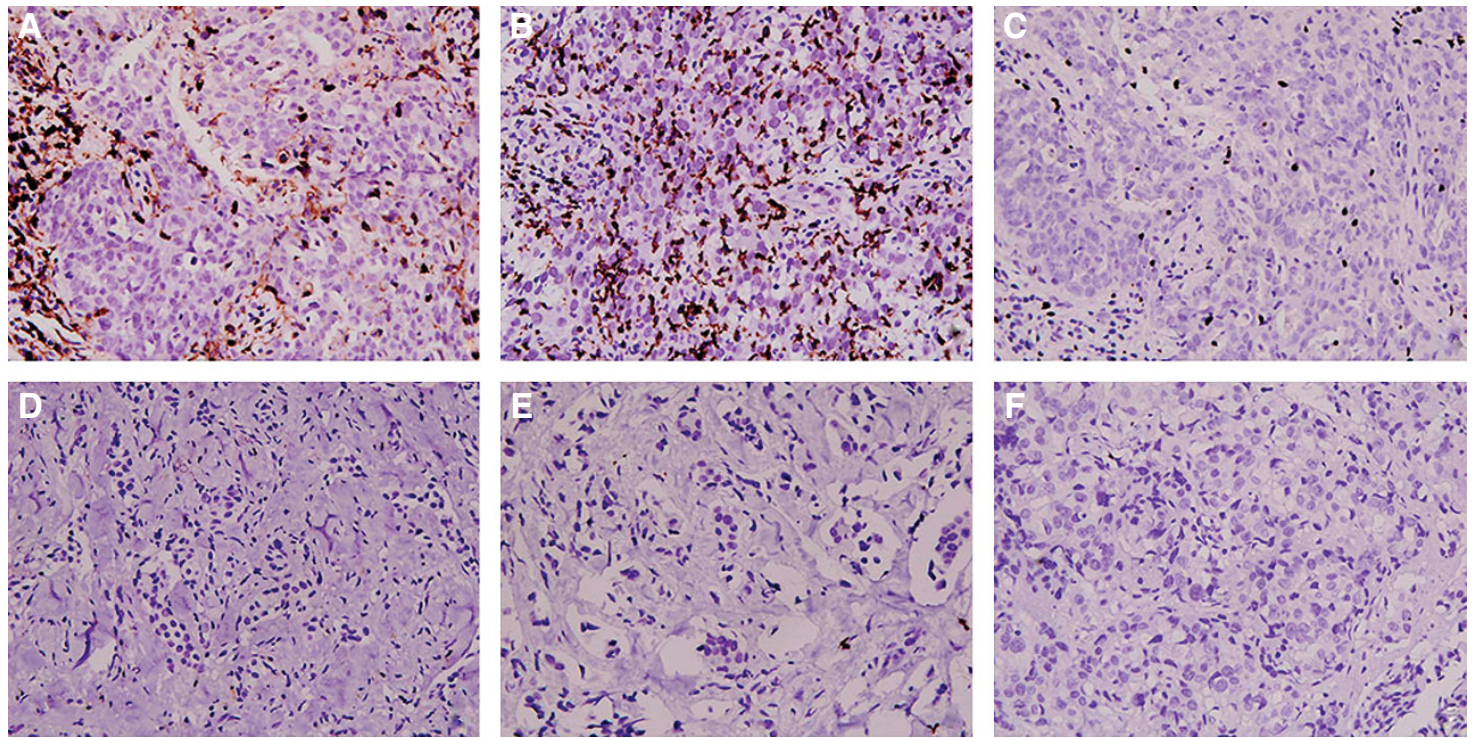

Figure 1. Intratumoural infiltration of CD4 +, CD8 +, and FOXP3 + T lymphocytes. High levels of infiltration of CD4 +, CD8 +, and FOXP3 + T lymphocytes $(\mathbf{A}-\mathbf{C})$ are seen in some tumours while in others there is almost no infiltration (D-F).

Table 2. Association of subsets of tumour-infiltrating lymphocytes with clinicopathological characteristics of tumour

\begin{tabular}{|c|c|c|c|c|c|c|c|c|c|}
\hline & \multicolumn{2}{|c|}{ CD4 + TILs } & & \multicolumn{2}{|c|}{ CD8 + TILs } & & \multicolumn{2}{|c|}{ FOXP3 + TILs } & \\
\hline & Low & High & & Low & High & & Low & High & \\
\hline Clinicopathological characteristics & $\mathbf{N}(\%)$ & N (\%) & P-value & $N(\%)$ & $\mathbf{N}(\%)$ & P-value & $\mathbf{N}(\%)$ & $\mathbf{N}(\%)$ & P-value \\
\hline $\begin{array}{l}\text { Clinical stage } \\
\text { II } \\
\text { III }\end{array}$ & $\begin{array}{l}33(42.3) \\
45(57.7)\end{array}$ & $\begin{array}{l}45(60.0) \\
30(40.0)\end{array}$ & 0.029 & $\begin{array}{l}36(47.4) \\
40(52.6)\end{array}$ & $\begin{array}{l}42(54.5) \\
35(45.5)\end{array}$ & 0.375 & $\begin{array}{l}34(45.9) \\
40(54.1)\end{array}$ & $\begin{array}{l}44(55.7) \\
35(44.3)\end{array}$ & 0.228 \\
\hline $\begin{array}{l}\text { Histological grade } \\
\text { Low (I and II) } \\
\text { High (III) }\end{array}$ & $\begin{array}{l}62(79.5) \\
16(20.5)\end{array}$ & $\begin{array}{l}37(49.3) \\
38(50.7)\end{array}$ & $<0.001$ & $\begin{array}{l}58(76.3) \\
18(23.7)\end{array}$ & $\begin{array}{l}41(53.2) \\
36(46.8)\end{array}$ & 0.003 & $\begin{array}{l}57(77.0) \\
17(23.0)\end{array}$ & $\begin{array}{l}42(53.2) \\
37(46.8)\end{array}$ & 0.002 \\
\hline $\begin{array}{l}\text { Estrogen receptor } \\
\text { Negative } \\
\text { Positive }\end{array}$ & $\begin{array}{l}19(24.4) \\
59(75.6)\end{array}$ & $\begin{array}{l}34(45.3) \\
41(54.7)\end{array}$ & 0.006 & $\begin{array}{l}15(19.7) \\
61(80.3)\end{array}$ & $\begin{array}{l}38(49.4) \\
39(50.6)\end{array}$ & $<0.001$ & $\begin{array}{l}16(21.6) \\
58(78.4)\end{array}$ & $\begin{array}{l}37(46.8) \\
42(53.2)\end{array}$ & 0.001 \\
\hline $\begin{array}{l}\text { HER2 status } \\
\text { Negative } \\
\text { Positive }\end{array}$ & $\begin{array}{l}59(75.6) \\
19(24.4)\end{array}$ & $\begin{array}{l}59(78.7) \\
16(21.3)\end{array}$ & 0.656 & $\begin{array}{l}61(80.3) \\
15(19.7)\end{array}$ & $\begin{array}{l}57(74.0) \\
20(26.0)\end{array}$ & 0.358 & $\begin{array}{l}59(79.7) \\
15(20.3)\end{array}$ & $\begin{array}{l}59(74.7) \\
20(25.3)\end{array}$ & 0.458 \\
\hline $\begin{array}{l}\text { Subtype } \\
\text { Non-TN } \\
\text { TN }\end{array}$ & $\begin{array}{l}68(87.2) \\
10(12.8)\end{array}$ & $\begin{array}{l}47(62.7) \\
28(37.3)\end{array}$ & $<0.001$ & $\begin{array}{r}67(88.2) \\
9(11.8)\end{array}$ & $\begin{array}{l}48(62.3) \\
29(37.7)\end{array}$ & $<0.001$ & $\begin{array}{l}64(86.5) \\
10(13.5)\end{array}$ & $\begin{array}{l}51(64.6) \\
28(35.4)\end{array}$ & 0.002 \\
\hline $\begin{array}{l}\text { Ki-67 index } \\
\text { Low }(\leqslant 20 \%) \\
\text { High }(>20 \%)\end{array}$ & $\begin{array}{l}48(61.5) \\
30(38.5)\end{array}$ & $\begin{array}{l}28(37.3) \\
47(62.7)\end{array}$ & 0.003 & $\begin{array}{l}44(57.9) \\
32(42.1)\end{array}$ & $\begin{array}{l}32(41.6) \\
45(58.4)\end{array}$ & 0.043 & $\begin{array}{l}48(64.9) \\
26(35.1)\end{array}$ & $\begin{array}{l}28(35.4) \\
51(64.6)\end{array}$ & $<0.001$ \\
\hline
\end{tabular}

Correlation of TIL subsets with BCSC and EMT. To determine the relationship between TIL subsets and BCSC or EMT in the breast cancers, we analysed the correlation between levels of the TIL subsets and the expression of BCSC and EMT markers. The infiltration of $\mathrm{CD} 4+, \mathrm{CD} 8+$, and FOXP3 $+\mathrm{T}$ lymphocytes was highly correlated with each other $(P<0.001)$ and they were closely correlated with the BCSC phenotype and EMT (Table 3). A high level of CD4 + TILs were positively correlated with the presence of $\mathrm{CD} 44+/ \mathrm{CD} 24-(P=0.016)$ and ALDH1 $+(P=0.017)$ tumour cells, as well as the expression of vimentin $(P<0.001)$, smooth muscle actin $(P=0.009)$ and osteonectin $(P=0.002)$. Similarly, strong infiltration of CD8 + CTLs inter-correlated with the presence of $\mathrm{CD} 44+/ \mathrm{CD} 24-\quad(P<0.001)$ and $\mathrm{ALDH} 1+$ $(P=0.005)$ tumour cells and the expression of vimentin $(P=0.007)$ and osteonectin $(P=0.038)$ (Figure 2$)$. A high level of FOXP3 + TILs were also positively correlated with ALDH1 $(P=0.032)$ and vimentin $(P<0.001)$ expression.

As infiltration of CD $4+, \mathrm{CD} 8+$, and FOXP3 + T lymphocytes and expression of BCSC and EMT markers occurred mostly in TNBC (Supplementary Table S2), we further analysed the correlation of the TIL subsets with BCSC and EMT within the TNBC. Even within the TNBC, strong infiltration of CD4 + and 
Table 3. Correlation of subsets of tumour-infiltrating lymphocytes with breast cancer stem cells and epithelial-mesenchymal transition markers

\begin{tabular}{|c|c|c|c|c|c|c|}
\hline & \multicolumn{3}{|c|}{ Total } & \multicolumn{3}{|c|}{ TNBC } \\
\hline & CD4 + TILs & CD8 + TILs & FOXP3 + TILs & CD4 + TILs & CD8 + TILs & FOXP3 + TILs \\
\hline Markers & $\rho$ (P-value) & $\rho$ (P-value) & $\rho$ (P-value) & $\rho$ (P-value) & $\rho$ (P-value) & $\rho$ (P-value) \\
\hline \multicolumn{7}{|l|}{ TILs } \\
\hline \multicolumn{7}{|l|}{ BCSC markers } \\
\hline $\begin{array}{l}\text { CD44 +/CD24 - } \\
\text { ALDH1 }\end{array}$ & $\begin{array}{l}0.194(0.016) \\
0.193(0.017)\end{array}$ & $\begin{array}{l}0.296(<0.001) \\
0.225(0.005)\end{array}$ & $\begin{array}{l}0.134(0.098) \\
0.174(0.032)\end{array}$ & $\begin{array}{l}0.394(0.014) \\
0.192(0.247)\end{array}$ & $\begin{array}{l}0.423(0.008) \\
0.165(0.323)\end{array}$ & $\begin{array}{l}0.127(0.448) \\
0.052(0.757)\end{array}$ \\
\hline
\end{tabular}

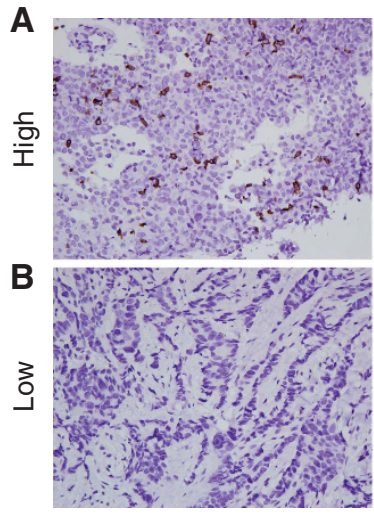

CD8+ T cell

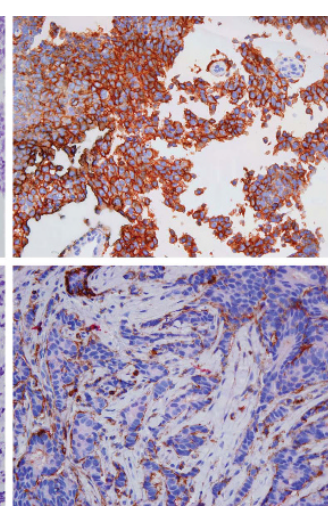

CD44+/CD24-

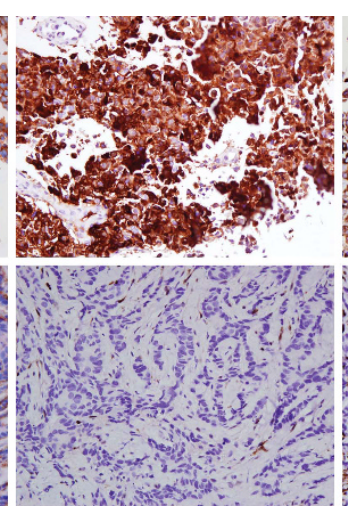

ALDH1

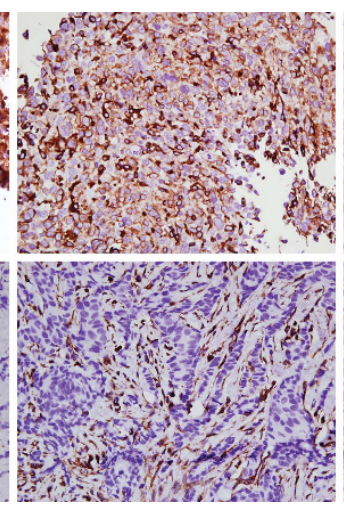

Vimentin

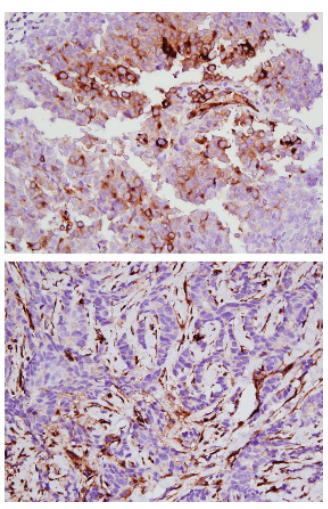

Osteonectin

Figure 2. Expression of breast cancer stem cell and epithelial-mesenchymal transition markers according to intratumoural infiltration of CD8 + cytotoxic T lymphocytes. (A) A representative example with infiltration of CD8 + CTLs into the tumour. CD44 +/CD24 - and ALDH1 + tumuor cells are present, as well as the expression of vimentin and osteonectin. (B) On the other hand, in this tumour with no infiltration of CD8 + CTLs, there is no expression of CD44 +/CD24 - , ALDH1, vimentin, or osteonectin.

CD8 $+\mathrm{T}$ cells was positively correlated with the presence of CD $44+/$ CD24 - tumour cells $(P=0.014, P=0.008$, respectively). In addition, strong infiltration of CD4 $+\mathrm{T}$ cells was positively correlated with vimentin expression $(P=0.008$; Table 3).

TIL subsets as predictive factors for pathological complete response. To assess the relationship between TIL subsets and pCR, we compared the numbers of intratumoural CD $4+, \mathrm{CD} 8+$ and FOXP3 $+\mathrm{T}$ cells in pCR and non-pCR cases. The patients who achieved pCR had significantly higher number of $\mathrm{CD} 4+, \mathrm{CD} 8+$, and FOXP3 + T-cell infiltrates than the non-pCR patients $(P=0.003, P<0.001, P=0.001$, respectively, Mann-Whitney $U$ test; Figure 3$)$. We also analysed the ratios of $\mathrm{CD} 8+/ \mathrm{CD} 4+$, $\mathrm{CD} 4+/ \mathrm{FOXP} 3+$, and $\mathrm{CD} 8+/ \mathrm{FOXP} 3+$ in the $\mathrm{pCR}$ and non-pCR groups. The $\mathrm{pCR}$ group showed significantly higher
$\mathrm{CD} 8+/ \mathrm{CD} 4+$ ratio $(P=0.018$, Mann-Whitney $U$ test $)$, but not those of $\mathrm{CD} 4+/ \mathrm{FOXP} 3+(P=0.277)$ and $\mathrm{CD} 8+/ \mathrm{FOXP} 3+$ $(P=0.297)$, than the non-PCR group (Figure 3$)$.

As a next step, the levels of CD $4+$, CD $8+$, and FOXP3 + TILs (low $v s$ high) together with various clinicopathological parameters, and BCSC and EMT markers, were subjected to univariate and multivariate logistic regression analyses to identify independent predictive factors for $\mathrm{pCR}$. In univariate analysis, strong infiltration of CD4 +, CD8 +, and FOXP3 + T cells, expression of vimentin and osteonectin, and classic predictive factors, including high histological grade and high Ki-67 proliferation index, ER negativity, and TN subtype, were found to be predictive factors for pCR (Table 4). However, in multivariate analysis, only high Ki67 index $(P=0.003$; OR, 9.786; 95\% CI, 2.121-45.149) and CD8 + TILs ( $P=0.003$; OR, 9.786; 95\% CI, 2.121-45.149) were independent predictive factors for pCR (Table 4). 
A

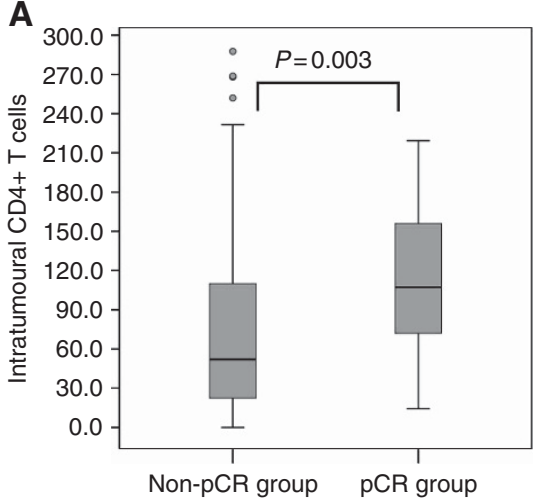

D

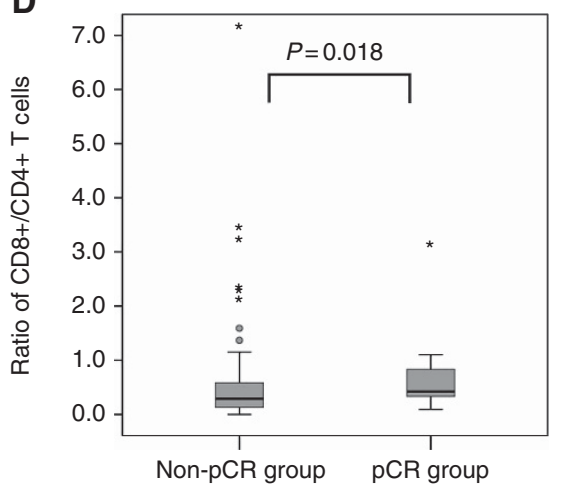

B

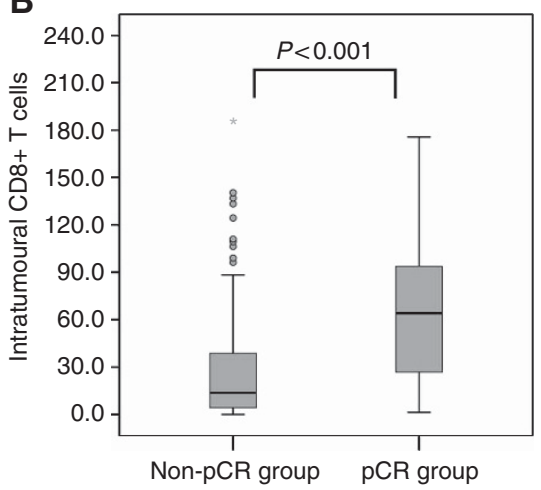

E

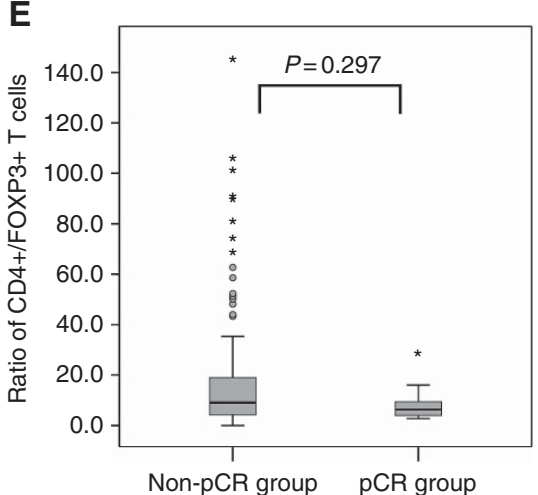

C

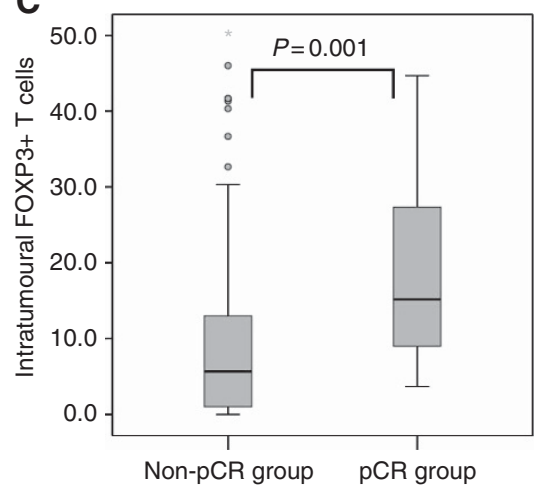

$\mathbf{F}$

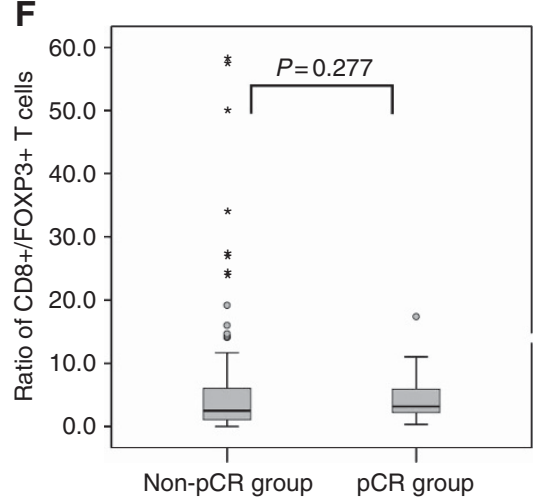

Figure 3. Box plots of the number of CD4+, CD8 +, and FOXP3 + tumour-infiltrating lymphocytes and the ratio of CD8 + /CD4+, CD4+/ FOXP3 +, and CD8 + /FOXP3 + T cells in relation to pathological complete response following primary systemic therapy. The group displaying a pathological complete response has higher numbers of (A) CD4 +, (B) CD8 + and (C) FOXP3 + tumour-infiltrating lymphocytes and (D) higher ratio of CD8 +/CD4 + T cells than the non-pCR group. There are no differences in the ratios of (E) CD4 +/FOXP3 + and (F) CD8 $+/ F O X P 3+T$ cells between the PCR and non-pCR groups. The box shows the 25th to 75th percentile, the horizontal line inside the box represents the median, the whiskers extend to the 10th and 90th percentiles, and the outlying black circles are individual data points outside the 10th and 90th percentiles.

Table 4. Predictive factors for pathological complete response in univariate and multivariate logistic regression analyses

\begin{tabular}{|c|c|c|c|c|c|c|c|}
\hline \multirow[b]{2}{*}{ Variable } & \multirow[b]{2}{*}{ Category } & \multicolumn{3}{|c|}{ Univariate analysis } & \multicolumn{3}{|c|}{ Multivariate analysis } \\
\hline & & OR & $95 \% \mathrm{Cl}$ & P-value & OR & $95 \% \mathrm{Cl}$ & P-value \\
\hline Histological grade & Low/high & 5.425 & $1.945-15.130$ & 0.001 & 1.637 & $0.425-6.306$ & 0.474 \\
\hline Estrogen receptor & Positive/negative & 5.624 & $2.015-15.700$ & 0.001 & 1.468 & $0.244-8.828$ & 0.675 \\
\hline Subtype & Non-TN/TN & 4.798 & $1.806-12.747$ & 0.002 & 0.683 & $0.120-3.888$ & 0.668 \\
\hline Ki-67 index & $\leqslant 20 \% />20 \%$ & 11.288 & $2.518-50.610$ & 0.002 & 9.786 & $2.121-45.149$ & 0.003 \\
\hline $\mathrm{CD} 4+$ TILs $^{\mathrm{a}}$ & Low/high & 7.328 & $2.019-26.206$ & 0.002 & 2.377 & $0.483-11.688$ & 0.287 \\
\hline $\mathrm{CD} 8+\mathrm{TILs}^{\mathrm{a}}$ & Low/high & 11.288 & $2.518-50.610$ & 0.002 & 9.786 & $2.121-45.149$ & 0.003 \\
\hline FOXP3 + TILs $^{a}$ & Low/high & 4.444 & $1.411-13.999$ & 0.011 & 0.292 & $0.039-2.212$ & 0.234 \\
\hline Vimentin & Negative/positive & 6.360 & $2.351-17.204$ & $<0.001$ & - & - & - \\
\hline Osteonectin & Negative/positive & 3.682 & $1.374-9.867$ & 0.010 & 1.561 & $0.444-5.483$ & 0.488 \\
\hline
\end{tabular}

Subgroup analyses according to breast cancer subtype, BCSC phenotype, EMT, and chemotherapeutic regimen. To confirm the association of CD8 + TILs with pCR irrespective of tumour subtype, we performed subgroup analyses in TNBC and nonTNBC (Supplementary Table S3). In TNBC, high levels of CD4+, $\mathrm{CD} 8+$, and FOXP3 + TILs were associated with $\mathrm{pCR}(P=0.037$, 
$P=0.038, P=0.037$, respectively). Other factors, including high Ki-67 proliferation index, and BCSC and EMT markers were not associated with pCR. In non-TNBC, positive HER2 status $(P<0.001)$, high Ki-67 proliferation index $(P=0.001)$, and a high level of CD8 + CTLs $(P=0.033)$ were associated with pCR.

As the CD $44+/ C D 24-$ BCSC phenotype was highly correlated with strong infiltration of CD4 + and $\mathrm{CD} 8+\mathrm{T}$ lymphocytes among total cancers and TNBC, we also performed subgroup analysis according to the $\mathrm{CD} 44+/ \mathrm{CD} 24-$ phenotype (Supplementary Table S4). In tumours with the CD $44+1$ $\mathrm{CD} 24$ - phenotype, high levels of CD4 +, CD8 + , and FOXP3 + T lymphocytes $(P=0.003, P=0.002$ and $P=0.020$, respectively) and expression of vimentin $(P<0.001)$ were associated with pCR in addition to the other classical predictive factors. However, in tumours without the CD44 +/CD24 - phenotype, only osteonectin expression $(P=0.040)$ was associated with pCR. CD8 + TILs tended to be high in the pCR group $(P=0.090)$.

Among the EMT markers examined, vimentin expression was strongly correlated with infiltration of $\mathrm{CD} 4+, \mathrm{CD} 8+$, and FOXP3 + TILs in total and in the TNBCs. Of the TIL subsets, only CD $8+$ TILs $(P=0.007)$ were significantly associated with $\mathrm{pCR}$ in tumours expressing vimentin. In tumours not expressing vimentin, the level of CD8 + CTLs tended to be high in the pCR group ( $P=0.137$; Supplementary Table S5).

Finally, in the subgroup analyses according to PST regimen, high levels of CD4,$+ \mathrm{CD} 8+$, and FOXP3 + TILs $(P=0.037$, $P=0.037, P=0.037$, respectively) were associated with $\mathrm{pCR}$ in patients treated with the ACT regimen. In the subgroups treated with the $\mathrm{AC}$ and $\mathrm{AD}$ regimens, there was no significant association between TILs and pCR. However, CD8 + TILs tended to be high in the pCR group $(P=0.076, \mathrm{AC}$ regimen; $P=0.158, \mathrm{AD}$ regimen; Supplementary Table S6).

\section{DISCUSSION}

Some chemotherapeutic agents, in particular anthracyclines, are supposed to induce specific immune responses that result in immunogenic cancer cell death or immunostimulatory side effects (Zitvogel et al, 2008). Therefore, such chemotherapy may act as an adjuvant for antitumour immunity (Menard et al, 2008). Actually, it has been reported that anthracycline-based chemotherapy promotes tumour infiltration by activated, IFN- $\gamma$-producing CD8 $+\mathrm{T}$ cells (Mattarollo et al, 2011), and anthracycline-based chemotherapy was found to be more efficient when it was administrated to immunocompetent mice than to immunodeficient mice transplanted with similar tumours (Casares et al, 2005). Taxanes also exert immunomodulatory effects on immune cells, some of which may lead to activation of innate and specific immune effectors (Carson et al, 2004; Javeed et al, 2009). In particular, paclitaxel simulates macrophages, which show direct cytotoxicity against tumour cells or indirect cytotoxicity by the secretion of cytokines to activate other immune cells to start anti-tumour immune response (Javeed et al, 2009). Thus, a higher host immune response against a tumour before treatment may enhance the effect of anthracyclineor antracycline/taxane-based chemotherapy in eliminating cancer cells via further activation of the immune system, which has already been sensitised to tumour antigen.

CD8 + CTLs are crucial components of tumour-specific cellular adaptive immunity, and studies have demonstrated that they are associated with patient survival in various cancers, including colorectal (Galon et al, 2006; Pages et al, 2009) and ovarian cancers (Sato et al, 2005). Recently, it was also reported that a high level of infiltration of CD8 + lymphocytes is an independent prognostic factor for favourable clinical outcome in breast cancer (DeNardo et al, 2011; Mahmoud et al, 2011; Liu et al, 2012). However, it has not been clear whether CD8 + CTLs are the key component of TILs associated with chemo-response. In this study, we showed that CD8 + TIL infiltration was an independent predictive factor for pCR in breast cancer patients treated with antracycline- or antracycline/taxane-based PST. Furthermore, in subgroup analysis, we found that the CD8 + TIL level was closely correlated with pCR irrespective of breast cancer subtype, CD44+/CD24- BCSC phenotype, EMT, and chemotherapeutic regimen. West et al (2011) reported that anthracycline-based adjuvant chemotherapy was beneficial in breast cancer patients with a high level of CD8+ TILs but not for those with a low level of CD8 + TILs. Mattarollo et al (2011) found that the therapeutic efficacy of doxorubicin treatment was dependent on CD8 + CTLs and IFN- $\gamma$ production in an experimental model of breast carcinoma in mice. Moreover, the levels of expression of $\mathrm{CD} 8 \alpha, \mathrm{CD} 8 \beta$, and IFN- $\gamma$ in human breast cancer samples before anthracycline chemotherapy were correlated with clinical response (Mattarollo et al, 2011). Collectively, these results suggest that $\mathrm{CD} 8+\mathrm{CTLs}$ are the primary component of TILs associated with response to anthracycline-based chemotherapy.

FOXP3 + Treg cells are known to disrupt anti-tumour immunity by suppressing the effector functions of various immune cells and have been implicated in escape of cancer cells from immunosurveillance (Ding and Zhou, 2012). Therefore, we expected that tumours with little infiltration of FOXP3 + Treg cells would be more likely to achieve pCR. However, contrary to this expectation, high-level infiltration of FOXP $3+$ T lymphocytes was associated with pCR, in accordance with previous studies (Oda et al, 2012; Lee et al, 2013). It has been reported that some chemotherapeutic agents, particularly cyclophosphamide, can inhibit tumour-protective Treg cells. Thus, it could be postulated that suppression of Treg inhibitory function by chemotherapy might be more profound in tumours with high levels of infiltration of FOXP3 + Treg cells, and this in turn would facilitate tumour attack by CD8 + CTLs and help to achieve pCR.

Although patients with TNBC showed the best response to PST, those with residual disease after PST have been reported to have the poorest survival (Carey et al, 2007; Liedtke et al, 2008; Bhargava et al, 2010). Therefore, in this aggressive type of breast cancer it is important to select those patients who will respond to a given chemotherapeutic regimen. Previously, Ono et al (2012) reported that high numbers of TILs were associated with higher pCR rates in TNBC. In this study, we showed that CD4 +, CD8 +, and FOXP3 + TILs were associated with pCR in TNBC, even though they were correlated with the CD44+/CD24- BCSC phenotype and vimentin expression within that subtype. However, our study has several limitations: the low number of TNBC cases, the use of a variety of different chemotherapeutic regimens, and its retrospective nature. Thus, further large studies will be needed to confirm the predictive value of TIL subsets, especially CD8+ CTLs, in chemotherapy of TNBCs.

Despite tumour immunosurveillance, tumour cells escape the innate and adaptive immune systems, and tumours develop. Thus, the idea of immunoediting, a concept used to describe the dynamic interaction of tumours with the immune system, has emerged (Dunn et al, 2002). It has been reported that immunoediting in a mouse model of breast cancer relapse gave rise to tumours that had undergone EMT and had characteristics of BCSCs (Knutson et al, 2006; Santisteban et al, 2009). Moreover, immune cells are known to produce various EMT mediators, including $\mathrm{TGF} \beta$ and $\mathrm{TNF} \alpha$ (Reiman et al, 2010). In this study, we showed for the first time that TILs were closely correlated with the BCSC phenotype and the expression of EMT markers in human breast cancer samples. Moreover, $\mathrm{CD} 4+$ or $\mathrm{CD} 8+$ TILs were correlated with CD44+/CD24 - BCSCs and vimentin expression even in the triple-negative subtype, supporting the hypothesis that TILs promote EMT and the BCSC phenotype (Reiman et al, 2010). However, the most important conclusion from this study is that 
CD8 + TILs influence the response to chemotherapy even in tumours containing CD44+/CD24- BCSCs and in which vimentin is expressed.

In our study, none of the patients with HER2-positive breast cancer was treated by neoadjuvant trastuzumab. Several studies showed that the addition of trastuzumab to neoadjuvant chemotherapy significantly increased pCR rate in HER2-positive breast cancer (Buzdar et al, 2005; Gianni et al, 2010; Ismael et al, 2012). However, despite its clinical benefits, the primary and/or acquired resistance to trastuzumab is frequent and thus requires new therapeutic approaches to improve its efficacy. Now, combination of active immunotherapy using various active vaccinal approaches and trastuzumab or lapatinib have been under clinical investigations in HER2-positive breast cancer (Milani et al, 2013). It was reported that addition of stimulated $\gamma \delta \mathrm{T}$ lymphocytes increased the efficacy of trastuzumab against HER2 + mammary carcinoma xenografts in mice (Capietto et al, 2011). Thus, further studies will be needed to evaluate the predictive role of TILs in response to HER2-targeted therapy, including trastuzuamb.

We found that the expression of some EMT markers, including vimentin and osteonectin, was significantly associated with the likelihood of pCR in breast cancer. This finding seems to indicate that EMT is associated with chemo-sensitivity, which appears to contradict its role in chemo-resistance. However, the expression of EMT markers is a characteristic of TNBC, as shown in this study, and these markers were not associated with pCR in our analysis according to breast cancer subtype. Taken together, these findings suggest that the reason why tumours with EMT features tend to achieve pCR is related to their association with TNBC not to their EMT features per se.

In summary, our study demonstrates that the presence of TILs is strongly associated with $\mathrm{pCR}$ and that the presence of $\mathrm{CD} 8+$ CTLs in particular is an independent predictive factor for pCR in breast cancer patients treated by antracycline- or antracycline/ taxane-based PST. Moreover, a high level of infiltration of CD8 + CTLs is correlated with pCR regardless of breast cancer subtype, BCSC phenotype, and EMT represented by vimentin expression. These findings suggest that CD8 + CTLs are the key component of TILs associated with chemo-response and might be used as a predictive marker to select patients who are more likely to respond to anthracycline- or antracycline/taxane-based PST.

\section{ACKNOWLEDGEMENTS}

This study was supported by a grant from the Korean Healthcare Technology R\&D Project, Ministry of Health, Welfare and Family Affairs, Republic of Korea (A070001) to SYP.

\section{REFERENCES}

Aaltomaa S, Lipponen P, Eskelinen M, Kosma VM, Marin S, Alhava E, Syrjanen K (1992) Lymphocyte infiltrates as a prognostic variable in female breast cancer. Eur J Cancer 28A: 859-864.

Bear HD, Anderson S, Brown A, Smith R, Mamounas EP, Fisher B, Margolese R, Theoret H, Soran A, Wickerham DL, Wolmark N (2003) The effect on tumor response of adding sequential preoperative docetaxel to preoperative doxorubicin and cyclophosphamide: preliminary results from National Surgical Adjuvant Breast and Bowel Project Protocol B-27. J Clin Oncol 21: 4165-4174.

Bhargava R, Beriwal S, Dabbs DJ, Ozbek U, Soran A, Johnson RR, Brufsky AM, Lembersky BC, Ahrendt GM (2010) Immunohistochemical surrogate markers of breast cancer molecular classes predicts response to neoadjuvant chemotherapy: a single institutional experience with 359 cases. Cancer 116: 1431-1439.
Buzdar AU, Ibrahim NK, Francis D, Booser DJ, Thomas ES, Theriault RL, Pusztai L, Green MC, Arun BK, Giordano SH, Cristofanilli M, Frye DK, Smith TL, Hunt KK, Singletary SE, Sahin AA, Ewer MS, Buchholz TA, Berry D, Hortobagyi GN (2005) Significantly higher pathologic complete remission rate after neoadjuvant therapy with trastuzumab, paclitaxel, and epirubicin chemotherapy: results of a randomized trial in human epidermal growth factor receptor 2-positive operable breast cancer. J Clin Oncol 23: 3676-3685.

Capietto AH, Martinet L, Fournie JJ (2011) Stimulated gammadelta T cells increase the in vivo efficacy of trastuzumab in HER-2 + breast cancer. J Immunol 187: 1031-1038.

Carey LA, Dees EC, Sawyer L, Gatti L, Moore DT, Collichio F, Ollila DW, Sartor CI, Graham ML, Perou CM (2007) The triple negative paradox: primary tumor chemosensitivity of breast cancer subtypes. Clin Cancer Res 13: 2329-2334.

Carson 3rd WE, Shapiro CL, Crespin TR, Thornton LM, Andersen BL (2004) Cellular immunity in breast cancer patients completing taxane treatment. Clin Cancer Res 10: 3401-3409.

Casares N, Pequignot MO, Tesniere A, Ghiringhelli F, Roux S, Chaput N, Schmitt E, Hamai A, Hervas-Stubbs S, Obeid M, Coutant F, Metivier D, Pichard E, Aucouturier P, Pierron G, Garrido C, Zitvogel L, Kroemer G (2005) Caspase-dependent immunogenicity of doxorubicin-induced tumor cell death. J Exp Med 202: 1691-1701.

Chollet P, Amat S, Cure H, de Latour M, Le Bouedec G, Mouret-Reynier MA, Ferriere JP, Achard JL, Dauplat J, Penault-Llorca F (2002) Prognostic significance of a complete pathological response after induction chemotherapy in operable breast cancer. Br J Cancer 86: 1041-1046.

Creighton CJ, Li X, Landis M, Dixon JM, Neumeister VM, Sjolund A, Rimm DL, Wong H, Rodriguez A, Herschkowitz JI, Fan C, Zhang X, He X, Pavlick A, Gutierrez MC, Renshaw L, Larionov AA, Faratian D, Hilsenbeck SG, Perou CM, Lewis MT, Rosen JM, Chang JC (2009) Residual breast cancers after conventional therapy display mesenchymal as well as tumor-initiating features. Proc Natl Acad Sci USA 106: $13820-13825$.

DeNardo DG, Brennan DJ, Rexhepaj E, Ruffell B, Shiao SL, Madden SF, Gallagher WM, Wadhwani N, Keil SD, Junaid SA, Rugo HS, Hwang ES, Jirstrom K, West BL, Coussens LM (2011) Leukocyte complexity predicts breast cancer survival and functionally regulates response to chemotherapy. Cancer Discov 1: 54-67.

DeNardo DG, Coussens LM (2007) Inflammation and breast cancer. Balancing immune response: crosstalk between adaptive and innate immune cells during breast cancer progression. Breast Cancer Res 9: 212.

Denkert C, Loibl S, Noske A, Roller M, Muller BM, Komor M, Budczies J, Darb-Esfahani S, Kronenwett R, Hanusch C, von Torne C, Weichert W, Engels K, Solbach C, Schrader I, Dietel M, von Minckwitz G (2010) Tumor-associated lymphocytes as an independent predictor of response to neoadjuvant chemotherapy in breast cancer. J Clin Oncol 28: 105-113.

Ding ZC, Zhou G (2012) Cytotoxic chemotherapy and CD4 + effector T cells: an emerging alliance for durable antitumor effects. Clin Dev Immunol 2012: 890178 .

Dunn GP, Bruce AT, Ikeda H, Old LJ, Schreiber RD (2002) Cancer immunoediting: from immunosurveillance to tumor escape. Nat Immunol 3: 991-998.

Galon J, Costes A, Sanchez-Cabo F, Kirilovsky A, Mlecnik B, Lagorce-Pages C, Tosolini M, Camus M, Berger A, Wind P, Zinzindohoue F, Bruneval P, Cugnenc PH, Trajanoski Z, Fridman WH, Pages F (2006) Type, density, and location of immune cells within human colorectal tumors predict clinical outcome. Science 313: 1960-1964.

Gianni L, Eiermann W, Semiglazov V, Manikhas A, Lluch A, Tjulandin S, Zambetti M, Vazquez F, Byakhow M, Lichinitser M, Climent MA, Ciruelos E, Ojeda B, Mansutti M, Bozhok A, Baronio R, Feyereislova A, Barton C, Valagussa P, Baselga J (2010) Neoadjuvant chemotherapy with trastuzumab followed by adjuvant trastuzumab versus neoadjuvant chemotherapy alone, in patients with HER2-positive locally advanced breast cancer (the NOAH trial): a randomised controlled superiority trial with a parallel HER2-negative cohort. Lancet 375: 377-384.

Goldhirsch A, Wood WC, Coates AS, Gelber RD, Thurlimann B, Senn HJ, Panel M (2011) Strategies for subtypes-dealing with the diversity of breast cancer: highlights of the St. Gallen International Expert Consensus on the Primary Therapy of Early Breast Cancer 2011. Ann Oncol 22: 1736-1747.

Hornychova H, Melichar B, Tomsova M, Mergancova J, Urminska H, Ryska A (2008) Tumor-infiltrating lymphocytes predict response to neoadjuvant 
chemotherapy in patients with breast carcinoma. Cancer Invest 26: 1024-1031.

Ismael G, Hegg R, Muehlbauer S, Heinzmann D, Lum B, Kim SB, Pienkowski T, Lichinitser M, Semiglazov V, Melichar B, Jackisch C (2012) Subcutaneous versus intravenous administration of (neo)adjuvant trastuzumab in patients with HER2-positive, clinical stage I-III breast cancer (HannaH study): a phase 3, open-label, multicentre, randomised trial. Lancet Oncol 13: 869-878.

Javeed A, Ashraf M, Riaz A, Ghafoor A, Afzal S, Mukhtar MM (2009) Paclitaxel and immune system. Eur J Pharm Sci 38: 283-290.

Knutson KL, Lu H, Stone B, Reiman JM, Behrens MD, Prosperi CM, Gad EA, Smorlesi A, Disis ML (2006) Immunoediting of cancers may lead to epithelial to mesenchymal transition. J Immunol 177: 1526-1533.

Ladoire S, Arnould L, Apetoh L, Coudert B, Martin F, Chauffert B, Fumoleau P, Ghiringhelli F (2008) Pathologic complete response to neoadjuvant chemotherapy of breast carcinoma is associated with the disappearance of tumor-infiltrating foxp $3+$ regulatory $\mathrm{T}$ cells. Clin Cancer Res 14: 2413-2420.

Lee HJ, Seo JY, Ahn JH, Ahn SH, Gong G (2013) Tumor-associated lymphocytes predict response to neoadjuvant chemotherapy in breast cancer patients. J Breast Cancer 16: 32-39.

Li X, Lewis MT, Huang J, Gutierrez C, Osborne CK, Wu MF, Hilsenbeck SG, Pavlick A, Zhang X, Chamness GC, Wong H, Rosen J, Chang JC (2008) Intrinsic resistance of tumorigenic breast cancer cells to chemotherapy. J Natl Cancer Inst 100: 672-679.

Liedtke C, Mazouni C, Hess KR, Andre F, Tordai A, Mejia JA, Symmans WF, Gonzalez-Angulo AM, Hennessy B, Green M, Cristofanilli M, Hortobagyi GN, Pusztai L (2008) Response to neoadjuvant therapy and long-term survival in patients with triple-negative breast cancer. J Clin Oncol 26: 1275-1281.

Liu S, Lachapelle J, Leung S, Gao D, Foulkes WD, Nielsen TO (2012) CD8 + lymphocyte infiltration is an independent favorable prognostic indicator in basal-like breast cancer. Breast Cancer Res 14: R48.

Mahmoud SM, Paish EC, Powe DG, Macmillan RD, Grainge MJ, Lee AH, Ellis IO, Green AR (2011) Tumor-infiltrating CD8 + lymphocytes predict clinical outcome in breast cancer. J Clin Oncol 29: 1949-1955.

Mani SA, Guo W, Liao MJ, Eaton EN, Ayyanan A, Zhou AY, Brooks M, Reinhard F, Zhang CC, Shipitsin M, Campbell LL, Polyak K, Brisken C, Yang J, Weinberg RA (2008) The epithelial-mesenchymal transition generates cells with properties of stem cells. Cell 133: 704-715.

Mattarollo SR, Loi S, Duret H, Ma Y, Zitvogel L, Smyth MJ (2011) Pivotal role of innate and adaptive immunity in anthracycline chemotherapy of established tumors. Cancer Res 71: 4809-4820.

Melichar B, Hornychova H, Kalabova H, Basova H, Mergancova J, Urminska H, Jandik P, Cervinka V, Laco J, Ryska A (2012) Increased efficacy of a dose-dense regimen of neoadjuvant chemotherapy in breast carcinoma: a retrospective analysis. Med Oncol 29: 2577-2585.

Menard C, Martin F, Apetoh L, Bouyer F, Ghiringhelli F (2008) Cancer chemotherapy: not only a direct cytotoxic effect, but also an adjuvant for antitumor immunity. Cancer Immunol Immunother 57: 1579-1587.

Milani A, Sangiolo D, Montemurro F, Aglietta M, Valabrega G (2013) Active immunotherapy in HER2 overexpressing breast cancer: current status and future perspectives. Ann Oncol 24: 1740-1748.

Oda N, Shimazu K, Naoi Y, Morimoto K, Shimomura A, Shimoda M, Kagara N, Maruyama N, Kim SJ, Noguchi S (2012) Intratumoral regulatory $\mathrm{T}$ cells as an independent predictive factor for pathological complete response to neoadjuvant paclitaxel followed by 5-FU/epirubicin/ cyclophosphamide in breast cancer patients. Breast Cancer Res Treat 136: 107-116.

Ono M, Tsuda H, Shimizu C, Yamamoto S, Shibata T, Yamamoto H, Hirata T, Yonemori K, Ando M, Tamura K, Katsumata N, Kinoshita T, Takiguchi Y, Tanzawa H, Fujiwara Y (2012) Tumor-infiltrating lymphocytes are correlated with response to neoadjuvant chemotherapy in triple-negative breast cancer. Breast Cancer Res Treat 132: 793-805.

Pages F, Kirilovsky A, Mlecnik B, Asslaber M, Tosolini M, Bindea G, Lagorce C, Wind P, Marliot F, Bruneval P, Zatloukal K, Trajanoski Z, Berger A, Fridman WH, Galon J (2009) In situ cytotoxic and memory T cells predict outcome in patients with early-stage colorectal cancer. J Clin Oncol 27: 5944-5951.

Park SY, Lee HE, Li H, Shipitsin M, Gelman R, Polyak K (2010) Heterogeneity for stem cell-related markers according to tumor subtype and histologic stage in breast cancer. Clin Cancer Res 16: 876-887.

Reiman JM, Knutson KL, Radisky DC (2010) Immune promotion of epithelial-mesenchymal transition and generation of breast cancer stem cells. Cancer Res 70: 3005-3008.

Reis-Filho JS, Tutt AN (2008) Triple negative tumours: a critical review. Histopathology 52: 108-118.

Santisteban M, Reiman JM, Asiedu MK, Behrens MD, Nassar A, Kalli KR, Haluska P, Ingle JN, Hartmann LC, Manjili MH, Radisky DC, Ferrone S, Knutson KL (2009) Immune-induced epithelial to mesenchymal transition in vivo generates breast cancer stem cells. Cancer Res 69: 2887-2895.

Sato E, Olson SH, Ahn J, Bundy B, Nishikawa H, Qian F, Jungbluth AA, Frosina D, Gnjatic S, Ambrosone C, Kepner J, Odunsi T, Ritter G, Lele S, Chen YT, Ohtani H, Old LJ, Odunsi K (2005) Intraepithelial CD8 + tumor-infiltrating lymphocytes and a high $\mathrm{CD} 8+$ /regulatory $\mathrm{T}$ cell ratio are associated with favorable prognosis in ovarian cancer. Proc Natl Acad Sci USA 102: 18538-18543.

Schmidt M, Bohm D, von Torne C, Steiner E, Puhl A, Pilch H, Lehr HA, Hengstler JG, Kolbl H, Gehrmann M (2008) The humoral immune system has a key prognostic impact in node-negative breast cancer. Cancer Res 68 : 5405-5413.

Singh A, Settleman J (2010) EMT, cancer stem cells and drug resistance: an emerging axis of evil in the war on cancer. Oncogene 29: 4741-4751.

Swann JB, Smyth MJ (2007) Immune surveillance of tumors. J Clin Invest 117: $1137-1146$

Tanei T, Morimoto K, Shimazu K, Kim SJ, Tanji Y, Taguchi T, Tamaki Y, Noguchi S (2009) Association of breast cancer stem cells identified by aldehyde dehydrogenase 1 expression with resistance to sequential Paclitaxel and epirubicin-based chemotherapy for breast cancers. Clin Cancer Res 15: 4234-4241.

West NR, Milne K, Truong PT, Macpherson N, Nelson BH, Watson PH (2011) Tumor-infiltrating lymphocytes predict response to anthracyclinebased chemotherapy in estrogen receptor-negative breast cancer. Breast Cancer Res 13: R126.

Zitvogel L, Apetoh L, Ghiringhelli F, Andre F, Tesniere A, Kroemer G (2008) The anticancer immune response: indispensable for therapeutic success? J Clin Invest 118: 1991-2001.

This work is published under the standard license to publish agreement. After 12 months the work will become freely available and the license terms will switch to a Creative Commons AttributionNonCommercial-Share Alike 3.0 Unported License.

Supplementary Information accompanies this paper on British Journal of Cancer website (http://www.nature.com/bjc) 